\title{
Chemical Composition, Antioxidant Potential, and Antimicrobial Activity of Elettaria cardamomum Essential 0il
}

\section{A R T I C L E I N F O}

\section{Article Type}

Original Research

\section{Authors}

Mohammad Molaveisi, $M S c^{1}$, Mahsa Noktehsanj Avval, $M S c^{2}$, Mostafa Shahidi Noghabi, $P h D^{3^{*}}$ Morteza Mohammadi, $P h D^{4}$

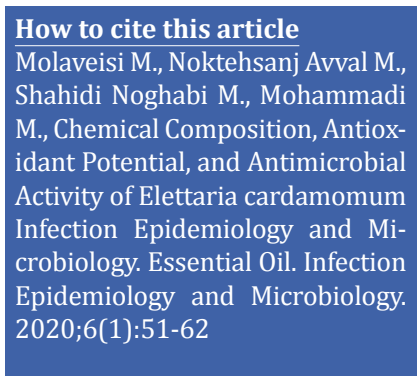

${ }^{1}$ Department of Food Chemistry, Research Institute of Food Science and Technology (RIFST), Mashhad, Iran. ${ }^{2}$ Department of Food Biotechnology, Research Institute of Food Science and Technology (RIFST), Mashhad, Iran. ${ }^{3}$ Department of Food Chemistry, Research Institute of Food Science and Technology (RIFST), Mashhad, Iran. ${ }^{4}$ Department of Food Processing, Research Institute of Food Science and Technology (RIFST), Mashhad, Iran.

\section{* Correspondence}

Address: Department of Food Chemistry, Research Institute of Food Science and Technology (RIFST), Mashhad, Iran.

m.shahidi@rifst.ac.ir

\section{Article History}

Received: January 25,2020

Accepted: March 10,2020

Published: March 22,2020

\section{A B S T R A C T}

Aims: The aim of this study was to investigate chemical composition, antioxidant potential, and antimicrobial activity of cardamom essential oil against Staphylococcus aureus, Escherichia coli, and Saccharomyces cerevisiae species.

Materials \& Methods: The chemical compositions of cardamom essential oil were identified by Gas Chromatography-Mass Spectrometry (GC-MS) device. Cardamom essential oil antioxidant activity was measured by 2, 2-diphenyl-1-picrylhydrazyl (DPPH) assay, and its total phenolic compounds (TPC) were measured by Folin-Ciocalteu reagent. The minimum inhibitory concentration (MIC) and minimum bactericidal concentration (MBC) of cardamom essential oil were determined using the serial-dilution method.

Findings: According to the GC-MS analysis results, 17 compounds were totally identified in cardamom essential oil, among which the most important compounds were 1, 8-cineole $(36.74 \%)$ and $\alpha$-terpinyl acetate (33.07\%). MICs obtained for S. aureus, E. coli, and $S$. cerevisiae were $12.50,25.00$, and $1.56 \mathrm{mg} / \mathrm{mL}$, respectively. Also, MBC obtained for both $S$. aureus and E. coli was $25 \mathrm{mg} / \mathrm{mL}$, while MBC for S. cerevisiae was $3.36 \mathrm{mg} / \mathrm{mL}$. Antioxidant activity measurement results showed that increasing the amount of cardamom essential oil reduced the amount of color and absorbance of DPPH solution to $517 \mathrm{~nm}$. The results also showed that the amount of TPC in cardamom essential oil was $214.35 \mathrm{mg}$ gallic acid per 100 g of dry material.

Conclusion: Cardamom essential oil used in this study showed antibacterial and anti-yeast activities against S. aureus, E. coli, and S. cerevisiae species. Antimicrobial effects of cardamom essential oil were predictable due to the presence of antimicrobial components in this oil.

Keywords: Cardamom essential oil, Total phenolic compound, Staphylococcus aureus, Escherichia coli, Saccharomyces cerevisiae.

\section{I T A T I O N L I N K S}

[1] Lone R, Shuab R, Malla NA, Gautam A, Koul K. Beneficial effects of arbuscular ... [2] Ustundag AO, Koca YO, Ozdogan M. THE RELATIONSHIP... [3] Saada M, Oueslati M, Msaada K, Snoussi M, Hamami M, Ksouri R. Changeability... [4] Solak A, Dyankova S. Antibacterial activity... [5] Sharafati-Chaleshtori R, Rokni N, Rafieian-Kopaei M, Drees F, Salehi E. Antioxidant and... [6] Tepe B, Donmez E, Unlu M, Candan F, Daferera D, Vardar-Unlu G, et al. Antimicrobial and... [7] Mouwakeh A, Radácsi P, Pluhár Z, Németh Zámboriné É, Muránszky G, Mohácsi-Farkas C, et al. Chemical... [8] Guo Q, Liu K, Deng W, Zhong B, Yang W, Chun J. Chemical composition and antimicrobial activity of... [9] Assem FM, El-Sayed HS, Matter MA, Hanafy MS, Amer AM. Effects of Carnation Essential Oil... [10] Ultee A, Bennik M, Moezelaar R. The phenolic hydroxyl group of carvacrol is essential for... [11] Lucchesi ME, Smadja J, Bradshaw S, Louw W, Chemat F. Solvent free... [12] Jadav KD, Mehta BM. Cardamom: Chemistry, Medicinal Properties, Applications in Dairy and Food... [13] Madhumita M, Guha P, Nag A. Extraction of betel... [14] Soltanian S, Mohamadi N, Rajaei P, Khodami M, Mohammadi M. ... [15] Mohammadi S, Piri K, Dinarvand M. Identification of Chemical Compositions in Some Medicinal... [16] Pertiwi D, Hafiz I, Salma R. Antibacterial... [17] Ouedrhiri W, Balouiri M, Bouhdid S, Harki EH, Moja S, Greche H. Antioxidant and... [18] Carvalho R, Carollo C, de Magalhães J, Palumbo J, Boaretto A, e Sá IN, et al. Antibacterial... [19] Aumeeruddy-Elalfi Z, Gurib-Fakim A, Mahomoodally MF. ... [20] Molaveisi M, Beigbabaei A, Akbari E, Noghabi MS, Mohamadi M. ... [21] Nekoei M, Mohammadhosseini M. Chemical composition of the essential oils and volatiles of... [22] Dutta S, Bhattacharjee P. Microencapsulation of enzyme-assisted supercritical... [23] Amma K, Rani MP, Sasidharan I, Nisha VNP. Chemical composition, flavonoid-phenolic... [24] Asghar A, Butt MS, Shahid M, Huang Q. ... [25] Zhang H, Wu J, Guo X. Effects of antimicrobial and antioxidant activities of... [26] Islam S, Rahman A, Sheikh MI, Rahman M, Jamal AHM, Alam F. In vitro antibacterial... [27] Sharafati-Chaleshtor F, Sharafati-Chaleshtori R. In vitro... [28] Naeini A, Naseri M, Kamalinejad M, Khoshzaban F, Rajabian T, Nami H, et al. Study on... 


\section{Introduction}

Today, bacterial resistance to antibiotics has created a global problem in the treatment of infectious diseases. Recently, the use of medicinal plants has become very widespread due to their lower side effects so that about $25 \%$ of drugs used in the United States are derived from medicinal plants. Medicinal herbs as one of the main economic plants in traditional and modern medicine are used in raw or processed form. Factors such as the protective role of medicinal plants against human diseases, the World Health Organization prohibition on the use of synthetic drugs, and the side effects associated with these drugs have led to the increasing use of medicinal plants in recent years ${ }^{(1)}$.

Pathogenic bacteria or their enterotoxins have made foodborne illnesses as one of the most common diseases in the world. The enterotoxins produced by Staphylococcus aureus, Escherichia coli, Salmonella, Arsenia, and Clostridium species are responsible for gastrointestinal poisoning and its symptoms. Also, food spoilage caused by microorganisms could cause economic damage ${ }^{(2,3)}$. Due to the importance of food quality standards and public health, it is essential to control and inhibit the growth of pathogenic bacteria in foods. The use of natural antimicrobial preservatives is one of the most effective ways to control the growth of pathogenic bacteria in food (4).

Plant secondary metabolites such as essential oils have been broadly investigated for their antimicrobial effects. Plant oils have important properties such as insecticidal, antifungal, anti-parasitic, antibacterial, antiviral, antioxidant, and cytotoxic activities (5). Therefore, plant essential oils are widely used in the fields of pharmacology, microbiology, phytopathology, and food storage (6). Aromatic essential oils are obtained from aromatic plants organs and used as food flavors. In addition, these essential oils are applied to prevent bacteria and molds growth and also to increase the shelf life of processed foods in the human diet $(7,8)$.

Antioxidant activity is one of the most important properties of essential oils and their active compounds. The antimicrobial effects of essential oils are due to the increase in free radicals and lipids peroxidation, damaging cellular and mitochondrial walls of microorganism. Factors causing cellular degradation, cellular permeability, ions and cellular content leakage, and sensitive cellular materials excretion ultimately cause bacterial death ${ }^{(8)}$. Essential oils containing a high percentage of phenolic compounds, such as carvacrol, eugenol, and thymol, also have high antibacterial activity against food pathogens. Mechanism of essential oils action against food pathogens seems to be related to their phenolic compounds. These phenolic compounds often cause cytoplasmic membrane disturbance, proton movement, electron flow, active transmission, and cell content coagulation ${ }^{\left({ }^{8,9}\right)}$. Also, the presence of different compounds in essential oils causes a variety of antibacterial effects so that Ultee et al. (2002) stated that hydroxyl groups of thymol, carvacrol, p-cymene, and menthol compounds were significantly responsible for their antibacterial activity ${ }^{(10)}$.

Elettaria cardamomum Maton (Cardamom) is a native spice of Asia wetlands (especially Iran) and a stable plant belonging to the Zingiberaceae family. The seeds of cardamom essential oil have been widely used as food flavors, especially in Sweden, Norway, the United Kingdom, and Asia. Cardamom essential oil is composed of monoterpene compounds such as 1,8-cineole, $\alpha$-terpinyl acetate, linalool, linalyl acetate, $\alpha$-terpineol, and $\alpha$ - terpin-4-ol ${ }^{(11)}$. Cardamom essential oil has considerable properties such as antibacterial, disinfectant, anti-contraction, 
and anti-seizure activities ${ }^{(12)}$.

The analysis of essential oils is problematic because they are composed of hundreds of active compounds. The gas chromatography device is widely used to identify volatile compounds and to determine their chemical structure. Both polar and nonpolar materials could be used for the chromatography column liquid phase ${ }^{(13)}$. Gas chromatography is an excellent method for evaluating the essential oils compositions. The output of the chromatography column is transferred to the detector in order to be evaluated by operator. In this way, the real flavor of essential oil is detected and recorded (14).

Objectives: This study aimed to investigate chemical compositions, antioxidant potential, and antimicrobial activity of cardamom essential oil against $S$. aureus, $E$. coli, and Saccharomyces cerevisiae species. Also, this study aimed to determine total phenolic compounds (TPC) and MIC and MBC of cardamom essential oil. The chemical compositions of cardamom essential oil were identified by Gas ChromatographyMass Spectrometry (GC-MS) device. The minimum inhibitory concentration (MIC) and minimum bactericidal concentration (MBC) of cardamom essential oil were determined using the serial-dilution method.

\section{Materials and Methods}

Preparation and analysis of cardamom essential oil: The cardamom seeds were prepared from Mashhad city (Iran country) and approved by the botanists of Faculty of Pharmacy at Mashhad University of Medical Sciences. The seeds were dried in the shade, $200 \mathrm{~g}$ of their powder was transferred to a two-liter balloon, and to which distilled water was added to fill about two-thirds of its capacity. For distillation, the balloon content was connected to a Clevenger apparatus (Clevenger, Herbal Exir Co., Mashhad, Iran) for $5 \mathrm{hrs}$. After the extraction of essential oil, dehydration was carried out using anhydrous sodium sulfate (Merck, Germany), and the extracted essential oil (about $10 \mathrm{~mL}$ ) was stored in a dark container. The analysis was done on an HP7820A chromatography (Agilent Technologies Inc., USA) machine with a flame ionization detector using an HP-5 column $(30 \mathrm{~m} \times 0.32 \mathrm{~mm} \times 0.25$ $\mu \mathrm{m})^{(15)}$. The temperature of the injection chamber was $120^{\circ} \mathrm{C}$, the initial temperature of the oven was $40{ }^{\circ} \mathrm{C}$, which was increased to $180{ }^{\circ} \mathrm{C}$ at a rate of $6{ }^{\circ} \mathrm{C} / \mathrm{min}$. The oven temperature was kept at $180{ }^{\circ} \mathrm{C}$ for two min before increasing to $250^{\circ} \mathrm{C}$ at a rate of $30^{\circ} \mathrm{C} /$ min. The total time of each test was $12 \mathrm{~min}$. The flame ionization detector temperature was $300{ }^{\circ} \mathrm{C}$.

\section{Antimicrobial activity of cardamom essential oil}

Preparation of microbial strains: The microbial strains used in this study, including S. aureus (1112 PTCC), E. coli (1337 ATCC), and S. cerevisiae (5076 PTCC), were prepared as a ready-made culture from the microbiological laboratory of Food Science and Technology Research Institute in Mashhad. These strains were prepared the day before use. To prepare microbial strains, Gram-positive and Gram-negative pathogens were removed from 50\% Stok Glycerol at $-75{ }^{\circ} \mathrm{C}$ and regenerated at $37{ }^{\circ} \mathrm{C}$ in a MHB and trypticase soy liquid medium (Merck, Germany). The strains used in this study were identified and inoculated twice in liquid culture medium after defrosting. Also, $S$. cerevisiae yeast was cultured on a Sabouraud Dextrose Agar culture medium for 5 days and incubated at $24{ }^{\circ} \mathrm{C}$ under aerobic conditions.

Preparation of McFarland solution: In this research, the $0.5 \mathrm{McF}$ arland standards were used. The 0.5 McFarland standard is commonly used in clinical microbiology laboratories and prescribed to test antimicrobial ability and culture media 
performance. To prepare 0.5 McFarland solution, $99.5 \mathrm{~mL}$ of $1 \%$ sulfuric acid was mixed with $0.5 \mathrm{~mL}$ of $1 \%$ barium chloride. About 50-70 $\mu \mathrm{L}$ of inoculum was added to a test tube containing $2 \mathrm{~mL}$ of distilled water or ringer's solution to prepare $0.5 \mathrm{McF}$ arland solution. In the presence of a good lighting, the turbidity of test suspension could be visually compared with that of the McFarland standard. If the test suspension is too light, additional organisms could be inoculated, but if the test suspension is too turbid, it could be diluted by adding sufficient broth or saline to obtain a turbidity matched with that of the standard. Eventually, more bacteria were added to the bacterial suspension. The turbidity of $0.5 \mathrm{McF}$. standard was equal to $1.5 \times 10^{8} \mathrm{CFU} / \mathrm{mL}$ of bacteria, in order to reach a turbidity of $10^{6}$ $\mathrm{CFU} / \mathrm{mL}$, this solution was diluted twice ${ }^{(16)}$. Preparation of extract: A 50000 ppm stock solution was prepared from cardamom essential oil; of which $0.35 \mathrm{~g}$ was weighed and added to $7 \mathrm{~mL}$ of dimethyl sulfoxide (DMSO) solvent and $7 \mathrm{~mL}$ of ethanol solvent each. The prepared solutions were sterilized through a $0.22 \mu \mathrm{m}$ millipore-membrane filter and poured into the sterile tubes for further dilution ${ }^{(17)}$. About $2 \mathrm{~mL}$ of the filtered extract from the previous step (cardamom essential oil/ ethanol, and cardamom essential oil/ DMSO) was poured in a sterile tube and diluted, and this was continued to achieve half concentrations. Different concentrations of this oil were prepared, including 100000, 50000, 25000, 12500, 6250, 3125, 1562.5,
781.25, and 390.625 ppm, respectively.

Determination of antimicrobial properties: Determination of MIC using a dilution tube method: The dilution method with some modifications was used to determine MIC and MBC. Briefly, gentamicin was diluted into different concentrations $(0.005$, $0.006,0.007,0.008,0.009,0.01,0.015$ and $0.02 \mathrm{mg} / \mathrm{mL}$ ) in Muller-Hinton Broth (MHB, Oxoid) in sterile tubes. About $10 \mu \mathrm{L}$ of each strain (S. aureus, E. coli, and S. cerevisiae ) (0.5 McFarland standard ${ }^{(18)}$ ) was inoculated into the test tubes containing $1 \mathrm{~mL}$ of various concentrations of gentamicin in MHB. The tubes were incubated at $37^{\circ} \mathrm{C}$ for $24 \mathrm{hrs}$ and observed for growth or turbidity. Thereafter equal volumes of sterile nutrient broth were added into the test tubes and incubated further for $24 \mathrm{hrs}$ at $37^{\circ} \mathrm{C}$. Then the tubes and agar plates were examined for growth or turbidity using unaided eye. The turbidity of cardamom essential oil in DMSO solution was due to its insolubility into the tube wall; thus, the solvent was neglected (Fig. 1). The gentamicin antibiotic was used as an antimicrobial agent in the MIC test (Table 1). Serial dilutions were prepared from MuellerHinton Broth culture medium containing $0.35 \mathrm{~g}$ of MHB. About $1000 \mu \mathrm{L}$ of the prepared concentrate was added into a sterile falcon tube containing $950 \mu \mathrm{L}$ of $\mathrm{MHB}$ culture medium, and the subsequent dilutions were prepared from cardamom essential oil. Then $50 \mu \mathrm{L}$ of bacterial suspension equivalent to 0.5 McFarland standard containing $10^{8}$ bacteria per $\mathrm{mL}$ was added to the test tubes.

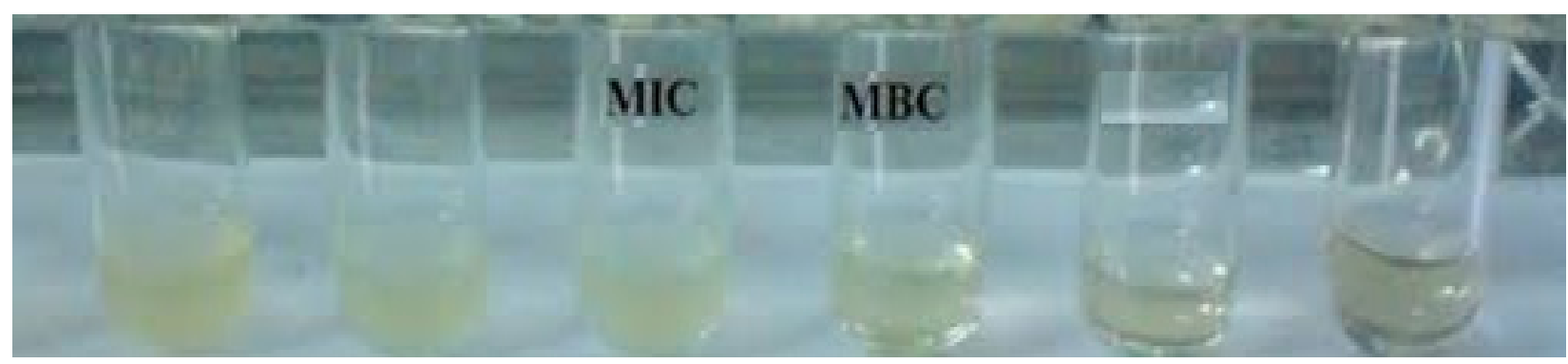

Figure 1) Dilution series using Muller Hinton Broth medium and $0.35 \mathrm{~g}$ of essential oil. 
In total, this test was carried out with a volume of $2000 \mu \mathrm{L}$ in each test tube. Similar experiments were carried out for positive, negative, and sterile controls. The samples were stored in an oven for 22-24 hrs at 37 ${ }^{\circ} \mathrm{C}$. The concentration of the first test tube without turbidity was reported as MIC. All experiments were repeated twice, and the mean of the obtained results was presented as MIC (Table 1 and 2).

Determination of MBC: MBC of cardamom essential oil was determined according to the MIC results. About $5 \mu \mathrm{L}$ of the material inside of each test tube was placed on the plates containing MHB culture medium of pathogenic bacteria, where bacterial growth was completely stopped. The mentioned experiments were performed with $10^{8}$ doses of bacteria, spot test was performed to determine the non-growth halos and the antagonistic and antimicrobial properties of cardamom essential oil. The plates were stored in an incubator for 22-24 hrs at 37 ${ }^{\circ} \mathrm{C}$. The concentrations in which there was no bacterial growth was considered as MBC ${ }^{(19)}$. Similar experiments were carried out for positive (MHB, ethanol, and treated bacteria) and negative (MHB, ethanol, and tested cardamom essential oil) controls.

Determination of antioxidant activity: For measuring DPPH (2,2 diphenyl-1picrylhydrazyl) radicals scavenging activity of cardamom essential oil, the method recommended by Molaveisi et al. (2019) (20) was used. Accordingly, $2 \mathrm{~mL}$ of different concentrations of essential oil (prepared in methanol) and $0.5 \mathrm{~mL}$ of Methanolic DPPH $(0.2 \mathrm{mM})$ were mixed and kept in a dark place at room temperature for $30 \mathrm{~min}$. Then absorbance was read at $517 \mathrm{~nm}$, and RSA (\%) was calculated using the following equation: $\mathrm{RSA}=\left(\mathrm{A}_{\text {Control }}-\mathrm{A}_{\text {sample }} / \mathrm{A}_{\text {Control }}\right) * 100$ Where $A_{\text {Control }}$ and $A_{\text {sample }}$ express the optical absorption of the non-essential oil and essential oil samples, respectively.
For better comparison, BHT (butylated hydroxytoluene) as a synthetic antioxidant and ascorbic acid as a natural antioxidant were used. To compare the radical scavenging power of essential oil, BHT, and ascorbic acid, the IC50 value was calculated, which is equal to the effective concentration of antioxidant for inhibiting 50\% of DPPH radicals.

Determination of Total Phenolic Compound (TPC): The amount of total phenolic compounds was measured according to the method described by Mohammadi et al. (2019) using FolinCiocalteu reagent (FCR) based on the FCR reduction in alkaline medium to form a blue complex ${ }^{(15)}$. In this test, $0.5 \mathrm{~mL}$ of cardamom essential oil was thoroughly mixed with 2.5 $\mathrm{mL}$ of $10 \%$ FCR and $2 \mathrm{~mL}$ of $7.5 \% \mathrm{Na}_{2} \mathrm{CO}_{3}$ $(\mathrm{w} / \mathrm{v})$ then placed in a dark place for $30 \mathrm{~min}$ at ambient temperature. The absorbance of the solution was read at $765 \mathrm{~nm}$ (UV-Visible Spectrophotometer, Shimadzu, Model: UV-160A, Japan). The standard curve was plotted with gallic acid (0-200 $\mu \mathrm{g} / \mathrm{mL})$, and TPC was calculated based on the amount (mg) of gallic acid per $100 \mathrm{~g}$ dry weight of plant.

Statistical Analysis: Using SPSS software Version 16.0, analysis of variance (ANOVA) and Duncan's multiple range test were carried out at 95\% confidence level to compare antimicrobial and antioxidant properties of cardamom essential oil. All measurements were performed in triplicate.

\section{Findings}

Tubes containing different concentrations of gentamicin showed no bacterial growth or any turbidity after 24 hrs of incubation. As shown in Table 1, E. coli showed turbidity after incubation in MHB with gentamicin at concentrations of 0.005 and $0.006 \mathrm{mg}$ / $\mathrm{mL}$ but not at higher concentrations, while $S$. aureus showed turbidity at $0.009 \mathrm{mg} / \mathrm{mL}$ 
gentamicin concentration but not at higher concentration. According to this test, the minimum and right amount of antibiotic used in the negative control treatments was examined separately for each organism. Antimicrobial activity of cardamom essential oil against the studied bacteria and yeast is showed in Table 2. As shown in Table 2, the MIC amounts of cardamom essential oil for $S$. aureus, E. coli, and $S$. cerevisiae species were $12.5,25$, and $1.56 \mathrm{mg} / \mathrm{mL}$, respectively. Also, Table 3 shows that the MBC amounts of cardamom essential oil for $S$. aureus, $E$. coli, and $S$. cerevisiae were 25,25 , and 3.12 $\mathrm{mg} / \mathrm{mL}$, respectively. The results showed that cardamom essential oil had excellent bacteriostatic and bactericidal effects at higher concentrations against the studied microbial agents.

Table 4 shows the inhibition zone of cardamom essential oil against the studied microorganisms. Inhibition zone diameter of $S$. aureus was significantly different from both $E$. coli and $S$. cerevisiae. The mean inhibition zone diameter of $S$. aureus was higher than that of E. coli and S. cerevisiae. Also, the mean inhibition zone diameter of E. coli was higher than that of $S$. cerevisiae. The MIC value of cardamom essential oil against the bacteria and yeast under study ranged from 1.56 to $25.00 \mathrm{mg} / \mathrm{mL}$, whereas the MBC value of cardamom essential oil against them was varied from 12.30 to 12.00 $\mathrm{mg} / \mathrm{mL}$. Based on the obtained results, the cardamom essential oil had a lower effect on $S$. aureus and $E$. coli bacteria than on $S$. cerevisiae yeast, and among the bacteria, the sensitivity of $S$. aureus was higher than E. coli. Also, cardamom essential oil had the same toxic effect on the bacteria, but its

Table 1) Inhibition pattern of E. coli, S. aureus, and S. cerevisiae using different concentrations of gentamicin in broth after $24 \mathrm{hrs}$ of incubation at $37^{\circ} \mathrm{C}$.

\begin{tabular}{lcccccccc}
\hline Gentamicin conc. (mg/mL) & $\mathbf{0 . 0 0 5}$ & $\mathbf{0 . 0 0 6}$ & $\mathbf{0 . 0 0 7}$ & $\mathbf{0 . 0 0 8}$ & $\mathbf{0 . 0 0 9}$ & $\mathbf{0 . 0 1}$ & $\mathbf{0 . 0 1 5}$ & $\mathbf{0 . 0 2}$ \\
\hline S. aureus $10^{8} \mathrm{CFU} / \mathrm{mL}$ & + & + & + & + & + & - & - & - \\
E. coli $10^{8} \mathrm{CFU} / \mathrm{mL}$ & + & + & - & - & - & - & - & - \\
S. cerevisiae $10^{8} \mathrm{CFU} / \mathrm{mL}$ & + & + & + & - & - & - & - \\
\hline -: No growth +: Growth
\end{tabular}

Table 2) Minimum inhibitory concentration (MIC) of cardamom essential oil (mg/mL).

\begin{tabular}{|c|c|c|c|c|c|c|c|c|c|}
\hline Concentration $\left(10^{8} \mathrm{CFU} / \mathrm{mL}\right)$ & 0.39 & 0.78 & 1.56 & 3.12 & 6.25 & 12.5 & 25 & 50 & 100 \\
\hline S. aureus & + & + & + & + & + & - & - & - & - \\
\hline E. coli & + & + & + & + & + & + & - & - & - \\
\hline S. cerevisiae & + & + & - & - & - & - & - & - & - \\
\hline
\end{tabular}

Table 3) Minimum bactericidal concentration (MBC) of cardamom essential oil (mg/mL).

\begin{tabular}{lccccccccc}
\hline Concentration $\left(\mathbf{1 0} \mathbf{C F U}^{\mathbf{C}} \mathbf{\mathrm { ml }}\right)$ & $\mathbf{0 . 3 9}$ & $\mathbf{0 . 7 8}$ & $\mathbf{1 . 5 6}$ & $\mathbf{3 . 1 2}$ & $\mathbf{6 . 2 5}$ & $\mathbf{1 2 . 5}$ & $\mathbf{2 5}$ & $\mathbf{5 0}$ & $\mathbf{1 0 0}$ \\
\hline S. aureus & + & + & + & + & + & + & - & - & - \\
E. coli & + & + & + & + & + & + & - & - & - \\
S. cerevisiae & + & + & + & - & - & - & - & - & - \\
\hline
\end{tabular}


Table 4) The antimicrobial activity of cardamom essential oil (mm).

\begin{tabular}{llll}
\hline Microorganisms & S. aureus $\left(\mathbf{1 0}^{\mathbf{8}} \mathbf{C F U} / \mathbf{m L}\right)$ & E. coli $\left(\mathbf{1 0}^{\mathbf{8}} \mathbf{C F U} / \mathbf{m L}\right)$ & S. cerevisiae $\left.\mathbf{( 1 0} \mathbf{~}^{\mathbf{C F U}} / \mathbf{m L}\right)$ \\
\hline Non-growth halos & $120.57 \mathrm{a}$ & $80.18 \mathrm{~b}$ & $70.31 \mathrm{~b}$ \\
\hline
\end{tabular}

a,b Values with different letters in the row differ significantly $(p<.05)$ by Duncan test.

toxicity was higher on the yeast than on the bacteria.

The active compounds of cardamom essential oil were identified by GC-MS device. The results obtained from the GC/ MS analysis of cardamom essential oil are presented in Table 5. The cardamom essential oil GC-MS analysis results showed the presence of 17 compounds in this oil, among which 1,8-cineole (36.74\%) and -terpinyl acetate (33.07\%) were the most detected compounds. Also, cardamom essential oil contained other compounds including o-cymene, d-limonene, sobrerol, and sobrerol 8-acetate in smaller quantities (Fig. 2).

\section{Discussion}

Antimicrobial activity of cardamom essential oil: Plant biological compounds are considered as an important branch of drug therapy. In many cases, although herbal drugs are more expensive but have fewer side effects than chemical drugs. Many studies have focused on replacing chemical protectants with natural and non-risk preservatives due to the risk and side effects associated with chemical materials. Also, according to the World Health Organization, about $80 \%$ of people in developed countries use medicinal plants for their therapy (21); although there is a need for further research in this regard. The increased published articles in this field explains the necessity and importance of this issue ${ }^{(8)}$.

The compounds identified by GC-MS were very similar to those compounds reported in the previous studies for other cardamom species essential oils ${ }^{(22)}$. Lucchesi et al. (2007) showed that cardamom essential oil contained 1,8-cineole, -terpinyl acetate, linalool, linalyl acetate, -terpineol, and -terpinen-4-ol compounds (11). Amma et al. (2010) exhibited that 1,8-cineole (20 to $60 \%$ ) and -terpinyl acetate (20 to $55 \%$ ) were the most frequently identified components in cardamom essential oil ${ }^{23)}$. Asghar et al. (2017) examined the green cardamom essential oil by GC-MS and reported -terpinyl acetate (38.4\%), 1,8-cineole (28.71\%), linalool acetate $(8.42 \%)$, sabinene (5.21\%), and linalool (3.97\%) as its major components ${ }^{(24)}$.

Due to the obtained results, the antibacterial effects of cardamom essential oil were acceptable. According to the previous

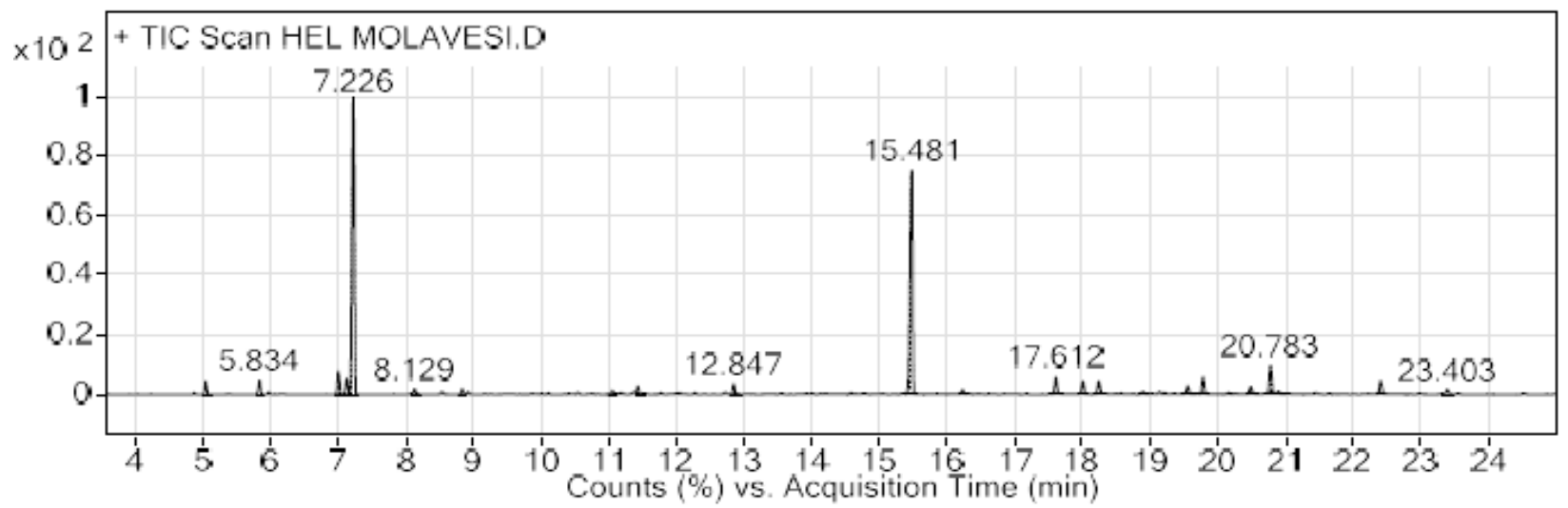

Figure 2) Chromatogram of cardamom essential oil by GC-MS method. 
Table 5: Chemical composition of cardamom essential oil (E. cardamomum).

\begin{tabular}{cccc}
\hline Sr. No. & Retention Time (min) & Name of Compound & Composition (\%) \\
\hline 1 & 5.043 & 3-Carene & 1.23 \\
2 & 5.834 & $\alpha$-Thujene & 1.42 \\
3 & 7.003 & o-Cymene & 2.53 \\
\hline 4 & 7.127 & D-Limonene & 1.87 \\
\hline 5 & 7.224 & 1,8-Cineole & 36.74 \\
\hline 6 & 8.128 & Sabinene hydrate & 0.66 \\
\hline 7 & 8.837 & Linalool & 0.59 \\
\hline 8 & 11.055 & Terpinen-4-ol & 0.42 \\
\hline 9 & 11.430 & $\alpha$-terpineol & 1.18 \\
10 & 12.849 & Formate & 1.33 \\
11 & 15.478 & $\alpha$-terpinyl acetate & 33.07 \\
12 & 16.230 & geranyl carbonate & 0.58 \\
13 & 18.009 & Sobrerol & 1.76 \\
14 & 18.245 & $\alpha$-acetate & 1.96 \\
15 & 19.787 & Sobrerol 8-acetate & 2.37 \\
16 & 20.491 & Sobrerol 8-acetate & 1.09 \\
17 & 20.785 & 2 -Cyclohexen-1-one & 4.24 \\
\hline & & Total & 93.04 \\
\hline
\end{tabular}

studies results, Gram-positive bacteria were more sensitive to essential oils under study than Gram-negative bacteria ${ }^{(8)}$. Also, the results indicated that $S$. aureus strains were more sensitive to cardamom essential oil than E. coli strains. The outer membranes surrounding the cell wall of Gram-negative bacteria could be a reason for their less resistance to essential oils. The outer membrane limits the release of hydrophobic materials through the lipopolysaccharides in the layers. In Gram-positive bacteria, the hydrophobic compounds of essential oils come into direct contact with double-layer phospholipids and apply their effect on this layer. This effect is manifested by an increase in ion permeability, leakage of vital cellular compounds, and disorder of bacterial enzyme system (3). Some researchers reported that there is a relationship between the chemical structures of some of the dominant components in essential oils and their antibacterial activity (8), consistent with the results of the present research. The high amounts of 1,8-cineole, -terpinyl acetate, d-limonene, and -terpineol compounds in cardamom essential oil could result in more antibacterial properties of cardamom essential oil (24). Although the mechanism of essential oils antimicrobial activity is not well known, the destruction of membrane by phenol groups and the chelating of metals by flavonoids could be considered as an inhibitory effect against 
microorganisms (25). The study of the mechanism of essential oils action has shown that these phenolic compounds increase membrane permeability and ultimately cause cell death. Also, these components have different antibacterial effects related to the hydroxyl groups of some of the essential oils constituents such as carvacrol, thymol, cymene, and menthol; therefore, it could be necessary to improve their antimicrobial properties (19).

Islam et al. (2010) examined antibacterial activity of mesthanol extract of the Elettaria cardamomum (L.) Maton seeds against 10 human pathogenic bacteria. They reported that the highest inhibitory activity was observed against $S$. typhi ${ }^{26)}$. Sharafati et al. (2017) reported that the green cardamom ethanolic extract had an antibacterial effect against Enterobacteriaceae ${ }^{(27)}$. Naeini et al. (2011) examined the antifungal effects of 50 herbal medicines using the disk diffusion method. They showed that essential oils such as cardamom essential oil had a strong antifungal effect (28).

Antioxidant activity of cardamom essential oil: The trend of radical scavenging ability (RSA) of cardamom essential oil with different concentrations is shown in Figure 3. Concentration of essential oil changed from 3000-10000 $\mu \mathrm{g} / \mathrm{mL}$, resulting in $15-92.57 \%$ RSA. This means that by increasing the amount of essential oil, the color of DPPH solution decreased, and its absorbance decreased to $517 \mathrm{~nm}$ while radical scavenging ability increased.

BHT and ascorbic acid had a propensity similar to cardamom essential oil. But the minimum, medium, and maximum concentrations of BHT and ascorbic acid, required to inhibit DPPH radicals, were much lower than that of essential oil. These differences were described by IC50 values of BHT, ascorbic acid, and cardamom essential oil; the less the amount of IC50, the higher the radical scavenging ability. Therefore,

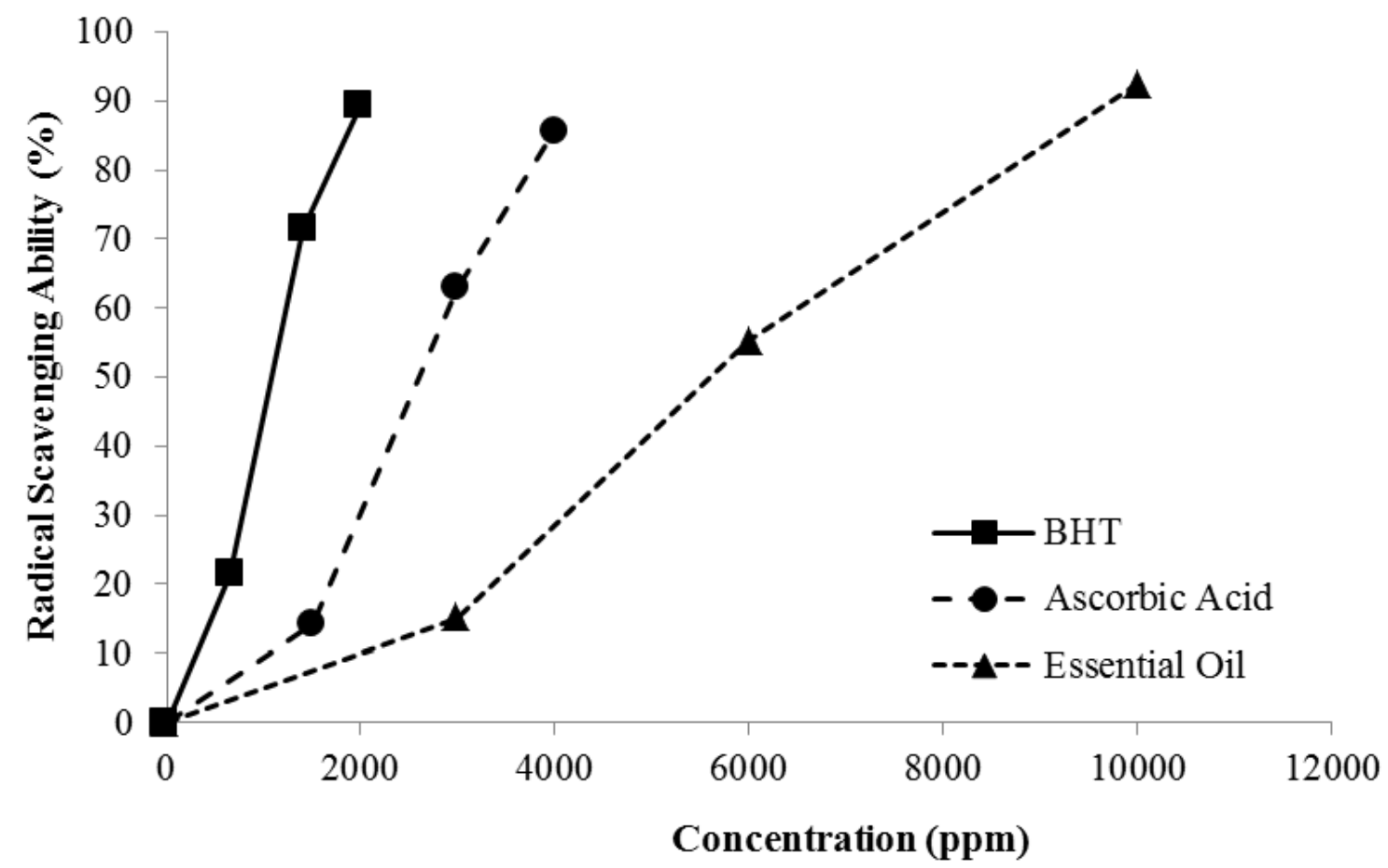

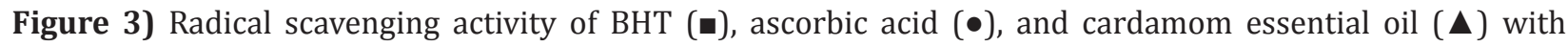
different concentrations. 


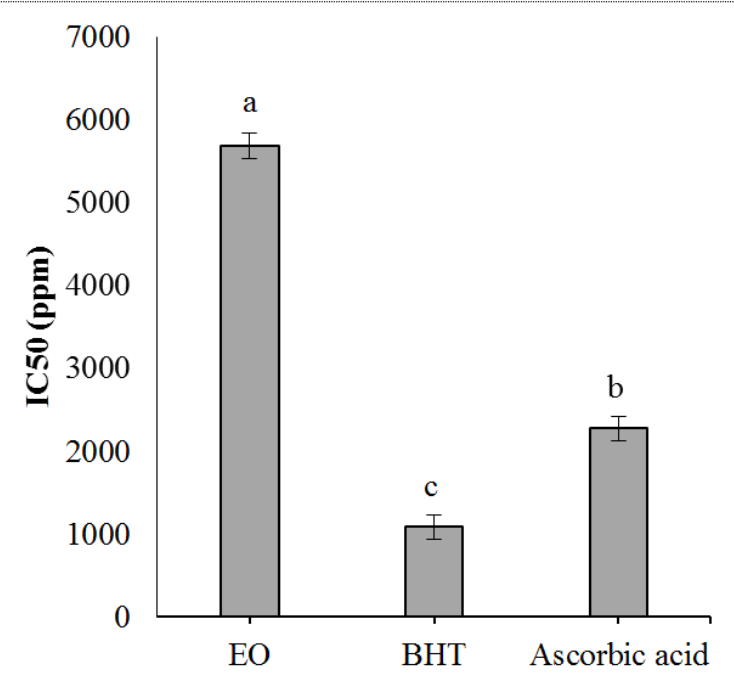

Figure 4) Amounts of IC50 for essential oil (EO), BHT, and ascorbic acid.

Total phenolic compound (TPC) of cardamom essential oil: Experiments showed that the amount of TPC in cardamom essential oil was $214.35 \mathrm{mg}$ gallic acid per $100 \mathrm{~g}$ of dry material. The amount of TPC in cardamom essential oil was not high in comparison with other extracts, for example, water extracts. Total phenolic compounds are more polar, and polar solvents such as water, ethanol, and acetonitrile are suitable for their extraction; thus, in cardamom essential oil, there wasn't very high level of TPC. This result was similar to that reported by Mohammadi et al. (2019) about the amount of TPC in essential oil extracted from pistachio wastes. They showed that TPCs in water extracts were more than TPCs in essential oil extracts ${ }^{(15)}$.

\section{Conclusion}

Cardamom essential oil used in this study showed antibacterial and anti-yeast effects against $S$. aureus, E. coli, and $S$. cerevisiae species. Antimicrobial effects of cardamom essential oil were predictable due to the presence of antimicrobial components in this oil. The inhibitory activity of cardamom essential oil was determined by MIC and MBC of this oil. The antimicrobial power of cardamom essential oil was high so that this oil could be used to control food bacteria and yeasts. The results obtained for antioxidant activity of cardamom essential oil showed that increasing the amount of essential oil reduced the amount of color and absorbance of DPPH solution to $517 \mathrm{~nm}$. The amount of TPC in cardamom essential oil was not high in comparison with water extracts.

Acknowledgements: This work was supported by both the Research Institute of Food Science and Technology (RIFST), Mashhad, Iran, and the Iranian National Science Foundation.

Ethical Permissions: None declared by Authors.

Conflicts of Interests: The authors declare no conflict of interest.

Authors Contribution: MM: Performed the experiments; contributed in the reagents, materials, analysis tools and data preparation; wrote the paper; MNA: Performed the experiments, wrote the paper; MSN: Conceived and designed the experiments, analyzed and interpreted data; MM: Analyzed and interpreted data, wrote the paper.

Fundings: The authors declare no conflict of interest.

\section{References}

1. Lone R, Shuab R, Malla NA, Gautam A, Koul K. Beneficial effects of arbuscular mycorrhizal fungi on underground modified stem propagule plants. J New Biologic Rep. 2016;5(1):41-51.

2. Ustundag AO, Koca YO, Ozdogan M. The Relationship Between Feed And Food Safety. Scientific Works Series C Veterinary Medicine. 2016;62(1):104-9.

3. Saada M, Oueslati M, Msaada K, Snoussi M, Hamami M, Ksouri R. Changeability in Retama raetam essential oils chemical composition, antioxidant and antimicrobial properties as affected 
by the physiological stage. Plant Biosystems-An International Journal Dealing with all Aspects of Plant Biology. 2018;152(6):1248-55.

4. Solak A, Dyankova S. Antibacterial activity of ethanol extracts of fifteen Bulgarian plants. Agricultural Science \& Technology (1313-8820). 2019;11(1).

5. Sharafati-Chaleshtori R, Rokni N, RafieianKopaei M, Drees F, Salehi E. Antioxidant and Antibacterial Activity of Basil (Ocimum basilicum L.) Essential Oil in Beef Burger. 2018; 17(4):817-826.

6. Tepe B, Donmez E, Unlu M, Candan F, Daferera D, Vardar-Unlu G, et al. Antimicrobial and antioxidative activities of the essential oils and methanol extracts of Salvia cryptantha (Montbret et Aucher ex Benth.) and Salvia multicaulis (Vahl). Food chemistry. 2004;84(4):519-25.

7. Mouwakeh A, Radácsi P, Pluhár Z, Németh Zámboriné É, Muránszky G, MohácsiFarkas $\mathrm{C}$, et al. Chemical composition and antimicrobial activity of Nigella sativa crude and essential oil. Acta Alimentaria. 2018;47(3):379-86.

8. Guo Q Liu K, Deng W, Zhong B, Yang W, Chun J. Chemical composition and antimicrobial activity of Gannan navel orange (Citrus sinensis Osbeck cv. Newhall) peel essential oils. Food science \& nutrition. 2018;6(6):1431-7.

9. Assem FM, El-Sayed HS, Matter MA, Hanafy MS, Amer AM. Effects of Carnation Essential Oil Extracted from Carnation Calli on Extending Shelf Life of Yoghurt. Plant Tissue Culture and Biotechnology. 2019;29(1):1-14.

10. Ultee A, Bennik M, Moezelaar R. The phenolic hydroxyl group of carvacrol is essential for action against the foodborne pathogen Bacillus cereus. Appl Environ Microbiol. 2002;68(4):1561-8.

11. Lucchesi ME, Smadja J, Bradshaw S, Louw W, Chemat F. Solvent free microwave extraction of Elletaria cardamomum L.: A multivariate study of a new technique for the extraction of essential oil. Journal of Food Engineering. 2007;79(3):1079-86.

12. Jadav KD, Mehta BM. Cardamom: Chemistry, Medicinal Properties, Applications in Dairy and Food Industry: A Review. Research \& Reviews: Journal of Dairy Science and Technology. 2019;7(3):9-19.

13. Madhumita M, Guha P, Nag A. Extraction of betel leaves (Piper betle L.) essential oil and its bio-actives identification: Process optimization, GC-MS analysis and anti-microbial activity. Industrial Crops and Products. 2019;138:111578.

14. Soltanian S, Mohamadi N, Rajaei P, Khodami M, Mohammadi M. Phytochemical composition, and cytotoxic, antioxidant, and antibacterial activity of the essential oil and methanol extract of Semenovia suffruticosa. Avicenna journal of phytomedicine. 2019;9(2):143.

15. Mohammadi S, Piri K, Dinarvand M. Identification of Chemical Compositions in Some Medicinal Plants by GC/MS Analysis. Lebanese Science Journal. 2019;20(1):161.

16. Pertiwi D, Hafiz I, Salma R. Antibacterial Activity of Gel of Ethanol Extract of Papaya Leaves (Carica papaya L.) againts Propionobacterium acnes. Indonesian Journal of Pharmaceutical and Clinical Research. 2019;2(1):01-6.

17. Ouedrhiri W, Balouiri M, Bouhdid S, Harki EH, Moja S, Greche H. Antioxidant and antibacterial activities of Pelargonium asperum and Ormenis mixta essential oils and their synergistic antibacterial effect. Environmental Science and Pollution Research. 2018;25(30):29860-7.

18. Carvalho R, Carollo $\mathrm{C}$, de Magalhães J, Palumbo J, Boaretto A, e Sá IN, et al. Antibacterial and antifungal activities 
of phenolic compound-enriched ethyl acetate fraction from Cochlospermum regium (mart. Et. Schr.) Pilger roots: mechanisms of action and synergism with tannin and gallic acid. South African Journal of Botany. 2018;114:181-7.

19. Aumeeruddy-Elalfi Z, Gurib-Fakim A, Mahomoodally MF. Chemical composition, antimicrobial and antibiotic potentiating activity of essential oils from 10 tropical medicinal plants from Mauritius. Journal of Herbal Medicine. 2016;6(2):88-95.

20. Molaveisi M, Beigbabaei A, Akbari E, Noghabi MS, Mohamadi M. Kinetics of temperature effect on antioxidant activity, phenolic compounds and color of Iranian jujube honey. Heliyon. 2019;5(1):e01129.

21. Nekoei M, Mohammadhosseini M. Chemical composition of the essential oils and volatiles of Salvia leriifolia by three different extraction methods prior to gas chromatographic-mass spectrometric determination: Comparison of HD with SFME and HS-SPME. Journal of Essential Oil Bearing Plants. 2017;20(2):410-25.

22. DuttaS, BhattacharjeeP.Microencapsulation of enzyme-assisted supercritical carbon dioxide extract of small cardamom by spray drying. Journal of Food Measurement and Characterization. 2017;11(1):310-9.

23. Amma K, Rani MP, Sasidharan I, Nisha VNP. Chemical composition, flavonoid- phenolic contents and radical scavenging activity of four major varieties of cardamom. Int J Biol Med Res. 2010;1(3):20-4.

24. Asghar A, Butt MS, Shahid M, Huang Q. Evaluating the antimicrobial potential of green cardamom essential oil focusing on quorum sensing inhibition of Chromobacterium violaceum. Journal of food science and technology. 2017;54(8):2306-15.

25. Zhang $\mathrm{H}$, Wu J, Guo X. Effects of antimicrobial and antioxidant activities of spice extracts on raw chicken meat quality. Food Science and Human Wellness. 2016;5(1):39-48.

26. Islam $S$, Rahman A, Sheikh MI, Rahman M, Jamal AHM, Alam F. In vitro antibacterial activity of methanol seed extract of elettaria cardamomum (L.) maton. Agriculturae Conspectus Scientificus. 2010;75(3):113-7.

27. Sharafati-ChaleshtorF,Sharafati-Chaleshtori R. In vitro antibacterial and antioxidant properties of Elettaria cardamomum Maton cardamom exhaustion and its effects with chitosan added on lamb storage. Veterinary Archives. 2017;87(3):301-15.

28. Naeini A, Naseri M, Kamalinejad M, Khoshzaban F, Rajabian T, Nami H, et al. Study on Anti_Candida Effects of Essential Oil and Extracts of Iranian Medicinal Plants, In Vitro. 2011. 